American Journal of Qualitative Research

December 2019, Vol.3 No. 2, pp. 87-96

https://doi.org/10.29333/ajqr/6436

(C) 2019 AJQR. http://www.ajqr.org
AMERICAN

JOURNAL OF QUALTATIVE

RESEARCH

\title{
Stained Glass Windows and Rainbows: My Journey to Socially Just Perceptions of and Actions toward LGBTQ Students
}

\author{
Kristina Andrews ${ }^{1}$ \\ Florida Gulf Coast University
}

\begin{abstract}
As a classroom teacher I have an ethical and moral obligation to provide a socially just and equitable learning environment and educational experience for all my students. Auto-ethnography is a research method grounded in modern philosophy. Auto-ethnography enables me to link the personal and cultural through inquiry and voice. In this article I explore the state of understanding my personal role and experiences as a conservative Christian educator in learning about and interacting with LGBTQ students. By reflecting and evaluating my personal experiences and attitudes I am able to identify my former biases, discriminatory tendencies, and stereotypes about LGBTQ community members. Therefore, throughout my analysis, I sought a means that would enable me to maintain my personal religious values while eliminating biases, stereotypes, and unjust perceptions. As a result, I recognize and embrace my religious identify as a conservative Christian educator who accepts my LGBTQ students without judgement or bias in order to be respectful, socially just, equitable, and nondiscriminatory.
\end{abstract}

KEYWORDS: Auto-Ethnography, Christian Educator, LGBTQ.

\section{Introduction}

Two pillars of socially just education are equity and social literacy. Equity encompasses the principle of fairness and social literacy promotes the resistance of the social evil of homophobia (Ayers, Quinn, \& Stovall, 2009). Throughout history people from many religions have contributed to combating oppression in the pursuit of greater social justice (Dulmus \& Sowers, 2012). Similar to the feelings of social workers (Dessel et al., 2017), I identified feelings of a harmonious semblance between my religious convictions and socially just ideals, and prided myself with treating all individuals fairly and equitably. Unfortunately, my "righteousness" encountered feelings of contention when I encountered members of the LGBTQ, as their identities and lifestyle did not align to my religious convictions.

Additionally, as a public school teacher and a graduate student seeking a doctoral degree in curriculum and instruction who emphasizes socially just and ethical educational opportunities for students, I recognize a need to examine my attitudes toward the LGBTQ community members and how my attitudes have changed over time. I have a professional ethical obligation to provide rich

${ }^{1}$ Corresponding author, e-mail: tinahannaha@gmail.com 
educational opportunities and serve all students regardless of their gender identity or sexual orientation. As a Christian who was taught to love all people unconditionally, I have an obligation to love all people, regardless of their choices or identities. The merging of these two obligations prompt me to seek the position of my current attitudes toward the LGBTQ members compared to what they were in the past and what they need to evolve into in the future in order to be a socially just and equitable teacher as well as a non-hypocritical Christian. An autoethnography methodology enables me to examine my past and present experiences and attitudes identified within my culture that is embedded within my community and society.

\section{Research Questions}

1. What factors influenced my attitudes toward LGBTQ community members?

2. In what ways did my attitudes toward LGBTQ community members change over time?

\section{Methodology}

I chose autoethnography methodology due to the highly personal nature of my experience. According to Chang (2016), autoethnographies are highly personal due to the researcher examining their interactions with other people within their socio-cultural context and how it has influenced their lived experiences. Autoethnography uses the personal experiences as the primary data to examine the experiences of the researcher. Chang grounds the conceptual framework of autoethnography methodology on four assumptions:

Culture is a group-orientated concept by which self is always connected with others; the reading and writing of self-narratives provides a window through which self and others can be examined and understood; telling one's story does not automatically result in the cultural understanding of self and others, which only grows out of in-depth cultural analysis and interpretation; and autoethnography is an excellent instructional tool to help not only social scientists but also practitioners-such as teachers, medical personnel, counselors, and human services workers-gain profound understanding of self and others and function more effectively with others from diverse cultural backgrounds. (p. 1)

Furthermore, Chang (2016) viewed personal memories as building blocks of autoethnographies due to the intimacy of the personal experience and transformation being shared. The key features of my autoethnography are personal memories of experiences, conversations with others of my shared culture, and self-reflections.

\section{Theoretical Framework}

The interpretive frameworks best reflected in this autoethnography is the social constructivist theory and the queer theory. Social constructivists seek an understanding of the world, making meanings from a complexity of views and through the interaction with others (Denzin \& Lincoln, 2011). The queer theory allows for the open inquiry of individual identities (Plummer, 2011) and has been influenced by the postmodern and post-structuralist thought that addresses the politics involved in the exclusion of individuals from society (Kirsch, 2000). Butler 
(1990, 1993) examined how culture informs an individual's understanding of presumed identity according to an interpretation of one's knowledge of Biology. However, she argued that it is possible to challenge our preconceived notions pertaining to sexuality by producing competing discourses that challenge the "truth" by exposing a falsehood that an original gender exists. Similarly, Sedgewick (1990) refused to accept people's experiences as monolithic, stating that different individual's experiences of desire, sex, and sexuality are complexly different. As a result, queer theorists seek to dismantle society's attempts to identify gender as singular, fixed or normal by deconstructing preconceived notions and redefining sexual identity as more than sexual acts and culture. (Watson, 2005). Halperin (1995) suggested that 'queer' should be seen as "an on-going process of self-constitution and self-transformation - a queer politics anchored in the perilous and shifting sands of non-identity, positionality, discursive reversibility and collective self-invention (p. 122). The "cultural web" in this study is conservative Christian teachers teaching in public high schools inclusive of LGBTQ members. I conversed with three other Christian teachers. Two of the teachers teach in the Midwest and one of the them teaches in southwest Florida. Myself and the other teachers identify as conservative Christians, meaning we read, believe, and seek to live the teachings in the King James Version Bible exclusively. We do not seek additional literature or biblical interpretations according to other people or clergy, rather we seek understanding through individual reading and meditation. We have experienced unity in what we have come to understand, and have identified our unified thoughts during times of fellowship when we meet. I elected to speak with these particular teachers due to our same beliefs and profession in an attempt to better understand how I can interact with students, such as the LGBTQ students, in a non-hypocritical and professional educational setting without compromising my religious convictions. This study offered opportunities to reflect on my past, present, and future perspectives of myself as a conservative Christian teacher immersed within a society that promotes equality for all persons and acceptance for the practices of individuals whose actions and lifestyle are contrary to my religious convictions.

\section{Personal Journey}

My journey began on a small dairy farm perched on top of Maple Ridge in West-Central Wisconsin. Our days consisted of morning chores-the sweet smell of corn dust and alfalfa hay wafting through the aisles of the barn, the sounds of the milk pump droning on while Dad gently tended to each cow as the warm milk flowed into the machines and to the parlor. After chores we gathered together around a homecooked breakfast meal prepared by our doting mother, who usually still had her barn clothes on. The duration of the day, after chores were completed and the cows were settled down in the pastures chewing on their cud, ranged from doing extra chores around the farm, reading books, or frolicking across the vast acres of fields or through the Maple woods. The approach of the evening found us assembling back in the barn, tending to the cows, and a final meal of meat and potatoes. Words were spoken softly, kindness was shared, and love was the language. Our attitudes and daily living were to reflect what Mom and Dad taught us was to be the first and most important part of our lives - Living to be like Jesus. Mornings, mealtimes, and bedtimes were all accompanied by prayer. Many mornings, the question was asked, "Did you read your bible?" or "Did you pray?" I recall less busy mornings where we would sit at the table or in the living room and read the King James Bible together. I knew by their example, that the bible was the most important book to my Mom and Dad, and because I believed that my parents' efforts to follow Jesus and live according to what was written in the Bible made our home a peaceful and loving place, I loved the bible just as much. 
In addition to watching my parents' practice our faith, I too sought to read and pray every day in order to have my own relationship with God. I grew to love reading and attending the meetings with the church because of the atmosphere of peace and love I felt there. There was and still is, a spirit that I feel that brings me peace and rest that cannot be explained according to science or anything natural. Throughout my teenage years and into my early $20 \mathrm{~s}$, I was not as diligent in reading my Bible, praying, and attending the church meetings and as a result, I lost the sense of peace and contentment that I had known up to that time. Feelings I experienced when I was seeking to practice my faith and those I experienced when I was not practicing my faith as well as, unexplainable emotions I felt when at church and when I prayed, increased and continue to increase my love for reading my Bible, praying to my God, and seeking to practice my faith.

During those readings and while sitting in church, I heard the story of Sodom and Gomorrah multiple times. God destroyed the cities with fire and brimstone because of homosexual activity (iniquity) among those there (Genesis 19, King James Version). I remember forming the understanding in my mind that homosexual activity was a sin. Reflecting back on my childhood, I recall church members conversing about homosexuality and concluding, according to their own revelations from meditations, that practicing it was a sin. Since our church is not founded on interpretations of a priest or pastor, but rather through the revelations of scripture to individuals during meditation, refuting what we believe is revealed by the holy spirit during meditation and found to be the same revelation to others, would be questioning if God can speak to us.

Homosexuality was also not accepted in my community which was comprised of German and Scandinavian dairy farmers and small town folks. Most families attended church regularly, change of any sort was not desired, and non-Christian was frowned upon. Ironically, in the community and at school, references made about homosexuals were generally negative, yet there weren't any individuals who identified as gay or homosexual. The public school I attended for the duration of my K-12 experience was situated in our little town of 500 people. My class had 33 students and although a few students joined us and then left, the 33 I started Kindergarten with were the same 33 I graduated with 13 years later. From my days at school I recall students using the word 'fag' as a demeaning term for someone they didn't like and if someone called someone a 'homo' it was meant to be insulting. A particular incident I was involved in occurred in $6^{\text {th }}$ grade. There was an elderly teacher's aide that would monitor us at recess. We had just learned in science class that humans are classified as Homo sapiens, so at recess my friend and I would run past the teacher's aide singing, "Mrs. Webb is a Homo sapiens!" When she would yell back that she wasn't we would laugh, continuing to antagonize her until we got in trouble. We were aware that Mrs. Webb was not informed of the differences between the terms Homo sapiens and homosexual and understood that she was hearing it in a derogatory manner. AIDS and HIV were discussed in my high school health class, but I do not recall it being associated with homosexuals. Perhaps this approach to teaching about the two diseases was to prevent conversations or teaching that would bring attention to homosexuality or perhaps it was because the teachers were not aware that AIDS and HIV were associated with homosexuality. I have no recollection of any of my teachers mentioning homosexuality nor do I recall having extensive conversations about homosexuality with classmates, neighbors, or friends. Homosexuality was not a topic discussed frequently or at any length in our home or with church or neighborhood friends, and conversations about it when they did occur, were abruptly terminated and referenced as being immoral and unnatural. The combination of biblical passages pertaining to homosexuality receiving the wrath of God and my community's response to homosexuality may have formed a level of degree of homophobia in my youth. In retrospect, my homophobia was based on homosexuality but not homosexual individuals. 
College may be perceived as a time of enlightenment for individuals like myself who seek to expose their minds to new experiences and perceptions. Upon graduating from high school, I ventured to the University of Wisconsin - River Falls, ready and willing to immerse myself within everything "the world offered." While I may not have been exposed to any members who would situate themselves in the LGBTQ community, for a dairy farm girl I credit my parents to opening my eyes to a global view. My mother was raised in the Bronx and my father had travelled around the world during his deployments to Vietnam and Operation Desert Storm. While I don't recall being encouraged to accept homosexuality, I do recall being encouraged to accept "everyone" despite their cultural differences. I believe it was this mindset I possessed the college summer I worked on the riverboats in Minneapolis, $\mathrm{MN}$, when a group with dinner cruise reservations who referred to themselves as "the company," joined us for the evening. "The company" was comprised of homosexuals, bisexuals, drag queens, and transsexuals. I recall having feelings of "repulsion" of their lifestyle and sexuality and felt uncomfortable while they were boarding the boat. However, despite my feelings toward their sexuality, I did not have feelings of resentment or hatred toward them as people. I recall a curiosity of who they were as people, and I believe my desire to learn about them and make sure they had a great evening on the cruise combined with their enthusiasm and excitement anticipating a fun evening, opened the way to developing kindred relationships with many that evening through extended conversations during the five hour cruise. There were a few passengers on the boat who asked me if I had ever been around so many gay people. When I told them that I had not and that I was not familiar with their lifestyle, I was impressed by their willingness to open up and tell me about themselves and share their lifestyle. Surprisingly enough, I was intrigued by their stories and our conversations flowed easily throughout the evening as we conversed, not according to our gender identities and sexuality, but as people with stories to tell. I do not recall a struggle of accepting them as people, but as I listened to them, I remember not being able to understand how they could desire a person of the same sex or a desire to be a person of a different gender than their biological identity. This experience was the first time I had met a person of the LGBTQ community, and I realized they were not as "scary" as I thought they would be. Of the many groups we accommodated that summer, "the company" was one of my favorites because of their zest and enthusiasm for life and their willingness to share their lifestyle and experiences with me when they knew that I was a "farm girl." .

The following year I enrolled in a National Student Exchange program. After two long days of traveling across the countryside to Laramie, Wyoming, I wound my way through the streets of my new college town, located my dorm, and began hauling my meager possessions up to my third floor room. While settling into my new surroundings, my roommate arrived. The first night we had a 'getting to know each other' session. Her first question was "What do you think of lesbians?" Sparing no words, I expressed my homophobia and disgust. A following question was "What do you think of bisexuals?" to which I responded, "That's even worse." Fortunately, my roommate did not isolate my response and decide to find a different roommate. I believe she noted my background and religious convictions which were all discussed as we talked the first night, and our conversations flowed easily as we laughed and enjoyed each other's company. As the semester progressed, I became aware that she was a bisexual. However, I recognized that we had developed into friends, thus her revealing to me that she was bisexual did not change my appreciation of our established friendship. She became a very dear friend who had a pivotal influence in my thinking and views. She and her girlfriend became my best friends during my time as an exchange student, and I realized that their sexual orientation did not make them persons undeserving of respect nor did it hinder my ability to be their friend. I found myself wondering how I could accept, love, and respect persons whose personal choices did not agree with my belief that their sexual orientation 
was the right thing to do according to Biblical passages. Thus, it was during that year that I began to question the conflict in my way of thinking and lead me to the beginning of my transformation of accepting the person, but not condoning their actions: Did I hate the sin or the sinner? "For all have sinned and come short of the glory of God" (Romans 3:3, King James Version), but "God shows his love for us in that while we were still sinners, Christ died for us" (Romans 5:8). Do I love everyone as a brother? "Anyone who does not love does not know God, because God is love" (I John 4:8, King James Version). Why had I decided that I am righteous enough to judge another? "Let him who is without sin among you be the first to throw a stone at her" (John 8:7, King James Version). These verses, along with others, began to change my attitude towards homosexuals. Whilst my religious convictions have yet to embrace and accept homosexuality as "right", my convictions continue to assist me in embracing and accepting homosexuals as persons deserving of respect and social justice. Reflecting on the verses mentioned, I began and continue to understand that an individual's choices in life and their chosen lifestyle is not mine to judge. Just as Jesus loved everyone throughout time, my job is to love. As a Christian who believes there is an eternal destiny for each person who has been conceived or who has lived outside the womb, I believe that I can pray to God that he could work with their spirit and speak to them individually and will judge them fairly when they pass into eternity. Therefore I can love and respect all persons, including those in the LGBTQ community, unconditionally and without judgement on their sexual identity or sexual orientation. This transformation was in my way of thinking. I have always believed, as an adult, that people must be treated kindly, but at this point I was beginning to realize that treating someone kindly did not mean my "heart" was in the right place, as I was judging them. Changing my way of thinking by not passing judgement on their choices or lifestyle opened up a new perspective on how people who think or act differently than me are deserving of actions and thoughts that are free from discrimination or disrespect.

Time has a way of slipping away and friendships fade. Several years passed before I would again find myself forming friendships with those who were members of the LGBTQ community. This time was different. This time I was a teacher in a small rural public high school and they were my students. As an educator I am aware of my ethical obligation to provide a fair and equitable educational experience that fosters deep learning and prepares my students for a global society, regardless of their gender identity or sexual orientation. As an individual who possesses an affinity to be compassionate and empathic, and who believes I have an obligation to be a socially just educator and mentor, I feel the only way I should treat my students is with respect, love, and fairness. However, when I encountered the students of the LGBTQ community who were in my class, after several years of no encounters with persons who identify as LGBTQ members, I respected and welcomed them, but struggled inside with how and if I was being fair and equitable to them. In other words, how could I strive to not only treat them fairly by treating them with respect and encouraging them to proliferate their academic abilities, not only because it was my responsibility to do so, but more importantly, because in my mind and heart I believed they were deserving of a socially just and equitable educational and personal experience? I was made aware that some of my LGBTQ students were faced with social (bullying) from peers who did not accept their sexual orientation and/or rejection by family members after revealing their gender identity and/or sexual orientation. I found myself again searching to see what my attitudes were and if my actions were because of my responsibility as an educator or if they were a result of a transformed way of thinking. While I was reflecting on my journey from being an uninformed homophobic individual due to my Christian upbringing and community impact, I strove to understand and identify my journey to how and why I had a changed my thinking and attitudes towards those in the LGBTQ community. Thus, I reached out to converse with other educators of my same religious 
beliefs in order to hear their perspectives and understand how they maintain their religious convictions while teaching in classrooms that are inclusive of LGBTQ students.

\section{Data}

"They are children who are confused and thus require more love and direction" (Person 1). "It is not up to me to decide if their choices are "right or wrong," my decision needs to pertain to what kind of education am I providing for all my students" (Person 2). As conservative Christian teachers immersed within a society that advocates for social justice for homosexuals and embraces their expressions of gender identity, each one of these teachers may struggle with how to identify and interact with their students in the LGBTQ community. Person one, a conservative Christian teacher in the upper Midwest, emphasized throughout the conversation that the "young people" who identify as LGBTQ or homosexual are confused as a result of society and "Hollywood" brainwashing them. The teacher felt moved to love the children, but the teacher felt a strong compelling need to pray for the students in order to try to "save" these students from their sin and a lost eternity. While Person 2 also viewed homosexuality as a sin, the teacher's focus was on the cognitive development and educational needs of the students. The teacher felt it was not in his jurisdiction as an educator to embrace or reject the students' choices pertaining to gender identity or sexual orientation, but to accept the child as a student and focus on the child's academic needs. The teacher mentioned that he prays for all his students to the end that they would get to "know" God and trusts that God and the Holy Spirit would guide each student as they needed to be guided.

\section{Findings}

I find my beliefs resonating with the expressions of these teachers. I have come to an understanding for myself that, as a Christian, I am not to judge another person based on their choices or lifestyle. However, I believe my responsibility as a Christian is to seek to understand what I believe and have come to recognize as right is practiced in my life, and follow Jesus' example of reaching out to or praying for those whose choices and actions do not align to what I feel is the right way to live. These statements may seem contrary to one another, but from my perspective, they are not. Praying for others according to what I have come to understand, leaves it in God's hand to intervene, allowing me to be the petitioner for a sinner, Jesus the intercessor, and God the one who would reach out to the individual. Therefore, I am at liberty as an educator to have the mindset that I can respect and treat all students equitably and strive to provide them with rich educational experiences that promote them in school and prepares them for their role in society.

As a result of my journey from a homophobic high school student and child to a teacher who has "adopted" (many of these students refer to me as their school mom) several students of the LGBTQ community, I can relate to each of the teachers I conversed with and where they are in their journey to embrace, with heart, students of the LGBTQ community. As Christians, when we believe that Heaven waiting for us when we pass from this mortal earth, we desire that our students will also be in Heaven with us and all people can only be there if we have been cleansed of our sins. Thus, we are moved to pray that our students will know the joys and feelings of hope we know from giving into the will of God and asking for forgiveness of sins and striving to live according to the teachings in the Bible. From my experiences throughout life when I found myself not practicing what I believed to be right according to my faith, I felt the loss of peace and contentment that I had when I would be reading, praying, and meditating. Therefore, I believe that 
people can be happy in life and they can be good people, but happy and good are not synonymous with peace and Godliness. I am aware that today's society does not provide teachers with the liberty to "preach" to our students, but I do believe that prayer in secret is heard by our God and he can do his work in many ways. The teachers I spoke with would agree that it is not about identifying the sin of students, as it is not our place to judge, but our "job" is to pray for them in all aspects of their life. Teachers do not teach religion or LGBTQ students. Teachers teach academic content, and we teach children. Conservative Christian teachers do not teach religion or LGBTQ students, we teach academic content, and we teach children.

My journey to understanding my attitudes and what influenced those attitudes toward LGBTQ community members and how it transformed over time is complex. This complexity is perhaps heightened when religion is factored in. Because religion and faith is based on an individual's personal experiences and understanding of things not seen and things that cannot be explained according to social theories or laws, my journey may be difficult to understand by those of unlike mind, and describing my journey may cause my reader to question or disagree with my personal expressions. Therefore, I find it imperative to state that I believe if you choose a religion, you accept and believe a way of thinking and living that may not be conforming or viewed as "right" by others of unlike faith or mind. However, when I believe that it is my faith and way of living that will determine where I spend eternal life, there can be no compromises or interjections of human reasoning that supersedes what I believe is revealed by the holy spirit. Considering this perspective and belief of mine, living amongst and interacting with those participating in a lifestyle I have come to believe is sinful, has been a journey that has not only impacted and influenced my mind, but has hopefully strengthened me and caused me to be more rooted in my faith and made me possess more of the spirit that Jesus had. The result of this would be less judgment on others, more love for others, more acceptance of others, and more kindness shown, not out of duty or professional responsibility, but because I realize I have my own sins to take to God and much work to do to gain God's approval for eternity. Therefore, my actions toward others and interactions with others must be socially just, loving, and kind. I acknowledge that what is in the heart and mind is what shows in the actions. Therefore, if I claim to be Christian, my actions and my thoughts must be in agreement.

\section{Conclusion}

Growing up on a small dairy farm in West Central Wisconsin provided me with a childhood that was safe and rich in family and community experiences. Unfortunately, it was this closed, sheltered environment in which I developed feelings of homophobia. My community and school did not provide learning opportunities to inform me about members of the LGBTQ community, rather the lack of knowledge about these individuals coupled with derogatory terms such as "fag" or "homo," made the lifestyle and people who participate in that lifestyle, one I did not view favorably. Having an even greater impact in terms of seeing it as wrong or sinful, was how I heard homosexuality referred to among church members. This view was further settled in my mind when I would read or hear about the story of Sodom and Gomorrah. Thankfully, when reflecting back on how I perceived members of the LGBTQ community then and how I perceive them now, my thinking has changed, but my faith has not. I have been able to recognize my misconceptions about the LGBTQ community as a result of interactions with gay, lesbian, and transsexual individuals and transform how I think about them, making my actions toward them genuine.

In my childhood days, I am unsure how I would have treated or responded to an individual of the LGBTQ community, as I was never in the situation where I knowingly interacted with them. 
Thankfully, my interactions only occurred after I learned that you did not mistreat people, regardless of what you thought of them. My interactions on the riverboats, my roommate and her girlfriend, and now my students, has had the most impact in assisting me in recognizing that being a Christian does not mean I judge a person according to what I believe is a sin. Rather, being a Christian means having the heart and mind to accept and love everyone despite their sins, as I too am a sinner. When my heart and mind only thinks the best of individuals and loves others, my actions toward them will be genuine when I am kind and promote social justice for them. My transformation as a conservative Christian and Christian educator from believing that members of the LGBTQ community are sinners and not worthy of respect and therefore should be avoided, to believing that they are worthy of respect and should be treated fairly and equitable, and it is not my place to judge them, has been a long, soul-searching journey. I am thankful that as a teacher in a public high school classroom, I no longer possess resentment, hatred, or disdain for individuals who, at one time in life, I may have discriminated against and who I may have denied the personal respect and academic opportunities they deserve, regardless of gender identity, sexual orientation, race, religion, or culture.

\section{Implications}

My autoethnography has implications for other classroom teachers or educational stakeholders who possess biases, act discriminatorily, or hold unjustified stereotypes against LGBTQ students. My personal journey and transformation may assist others by offering motivation or an approach to eliminate their unjust or inequitable attitudes and actions. Furthermore, for those whose attitudes are socially unjust or inequitable due to conservative Christian beliefs and practices, it provides insight into what may be a 'more Christian' approach and attitude toward all students, especially those whose beliefs differ from theirs - as may be the situation when interacting with LGBTQ community members.

\section{References}

Ayers, W., Quinn, T., \& Stovall, D. (2009). Handbook of social justice in education. New York, NY: Routledge.

Butler, J. (1990). Gender trouble: Feminism and the subversion of identity. London: Routledge. Butler, J. (1993). Bodies that matter: On the discursive limits of sex. London: Rougledge.

Chang, H. (2016). Autoethnography as method. New York, NY: Routledge.

Denzin, N. K., \& Lincoln, Y. S. (2011). Introduction: The discipline and practice of qualitative research. The SAGE Handbook of Qualitative Research (4th ed., pp. 1-19). Thousand Oaks, CA: Sage.

Dessel, A. B., Jacobsen, J., Levy, D. L. McCarty-Caplan, D. Lewis, T. O., \& Kaplan, L. E. (2017). LGBTQ topics and Christianity in social work: Tackling the tough questions. Social Work \& Christianity, 44(1), 11-30.

Dulmus, C. N., \& Sowers, K. M. (Eds.). (2012). The profession of social work: Guided by history, led by evidence. Hoboken, $\mathrm{NJ}$ : Wiley.

Halperin, D. (1995). Saint Foucault: Towards a gay hagiography. Oxford: Oxford University Press.

Kirsch, M. H. (2000). Queer theory and social change. New York, NY: Routledge. 
Plummer, K. (2011). Critical humanism and queer theory: Living with the tensions. In N. K. Denzin \& Y. S. Lincoln (Eds.), The SAGE Handbook of Qualitative Research (4th ed., pp. 195207). Thousand Oaks: Sage.

Sedgewick, E. (1990). The epistemology of the closet. Berkeley: University of California Press.

Watson, K. (2005). Queer theory. Group Analysis, 38(1), 67-81. doi:10.1177/0533316405049369

Manuscript received November 04, 2019 Final revision received December 08, 2019

Accepted December 09, 2019 